\title{
In Situ Investigation of the Bainitic Transformation from Deformed Austenite During Continuous Cooling in a Low Carbon Mn-Si-Cr-Mo Steel
}

\author{
WILLIAM LEMOS BEVILAQUA, JÉRÉMY EPP, HEINER MEYER, \\ ALEXANDRE DA SILVA ROCHA, and HANS ROELOFS
}

\begin{abstract}
The effects of hot deformation on the bainitic transformation of a low carbon steel during continuous cooling were comprehensively studied through in situ high-energy synchrotron $\mathrm{X}$-ray diffraction, dilatometry, and ex situ microstructural characterizations. The obtained results indicated that the prior deformation of austenite at $950{ }^{\circ} \mathrm{C}$ accelerates the bainite formation at the early stages. During the ongoing of the transformation, both the overall kinetics of bainite and carbon enrichment of austenite are lower in deformed austenite. The bainitic microstructure developed from deformed austenite is more refined and presents the same retained austenite content at room temperature with slightly lower carbon content when compared with the undeformed sample. Besides, a significant higher dilatation strain was measured during the bainitic transformation in the deformed sample, which can be explained by the crystallographic texture in hot deformed austenite. The evolution of the peak broadening of the $\{220\} \gamma$ and $\{211\} \alpha$ reflections during bainitic transformation are discussed in detail.
\end{abstract}

https://doi.org/10.1007/s11661-020-05800-6

(c) The Minerals, Metals \& Materials Society and ASM International 2020

\section{INTRODUCTION}

Continuously cooled bainitic steels for hot-rolled bars or forged components have been a topic of growing interest over the past 10 years ${ }^{[1]}$ In general, $\mathrm{Si}$ or $\mathrm{Al}$ alloyed steels are considered for such applications, since these elements strongly inhibit the carbide formation and lead to carbide-free bainite with an increased amount of retained austenite. ${ }^{[2]}$

The combination of strength from the microstructural constituent bainitic ferrite and ductility related to retained austenite of the new generation of low carbon bainitic steels can lead to a broad range of mechanical properties. Therefore, bainitic steels have the potential to replace conventional quenching and tempering processes applied after hot forging and uncontrolled cooling. Through the use of a continuous cooling transformation process, which is one primary interest in industrial schedules, ${ }^{[3]}$ a substantial reduction of

WILLIAM LEMOS BEVILAQUA and ALEXANDRE DA SILVA ROCHA are with Post-graduation Program in Mining, Metallurgical and Materials Engineering (PPGE3M), Federal University of Rio Grande do Sul (UFRGS), Av. Bento Gonçalves, 9500. Porto Alegre, CEP 91501-970, Brazil. Contact e-mail: bevilaquawilliam@gmail.com JÉRÉMY EPP and HEINER MEYER are with the Leibniz Institute for Materials Engineering IWT, Badgasteiner Str. 3, 28359 Bremen, Germany. HANS ROELOFS is with Swiss Steel AG, Emmenbrücke, Switzerland.

Manuscript submitted September 28, 2019.

Article published online May 6, 2020 energy consumption in manufacturing routes can be achieved, especially for the low and medium carbon content steels due to rapid bainite formation kinetics.

On the other hand, the use of hot deformation can affect the bainitic transformation in a complex way, leading to different results obtained in the literature that sometimes look contradictory, ${ }^{[4]}$ mainly considering the effect of prior deformation on the kinetics of phase transformation. In fact, the effects of deformation on the bainitic transformation, and the resulting microstructure are less studied than the effects of transformation temperature. ${ }^{[5]}$ Additionally, the carbon partitioning into austenite can be affected by the previous hot deformation, which has not been accurately studied in the literature during continuous cooling.

Few investigations using in situ high-energy X-ray diffraction (HEXRD) were reported on bainitic transformation in low carbon steels. Studies conducted with isothermal treatments ${ }^{[6]}$ show that carbon in the austenite becomes heterogeneous as the transformation progresses, leading to the different austenite morphologies (films and blocks). Similar behavior was also found for continuous cooling transformation, ${ }^{[7]}$ in which the overall transformation was described as a four-stage process when cooling rates lower than $0.75{ }^{\circ} \mathrm{C} / \mathrm{s}$ are applied. 
The effects of hot deformation on the bainitic transformation by continuous cooling have been only discussed in terms of dilatometry data, which is not capable of describing in detail the bainite formation and kinetics due to anisotropic dilatation effects from the variant selection. Through the in situ X-ray diffraction experiments, the full details on the evolution of phase transformation kinetics, carbon enrichment of austenite, and lattice defects can be reliably described. Additionally, in situ HEXRD experiments approaching the effects of deformation and subsequent continuous cooling process on bainite reaction are practically not addressed in the literature.

This work aims to present a detailed in situ characterization of the bainitic transformation during continuous cooling in a low carbon steel replicating a hot forging operation. The effects of hot deformation on the phase transformation kinetics have been investigated based on high-energy X-ray diffraction analysis. These investigations are complemented by SEM and EBSD analysis.

\section{EXPERIMENTAL PROCEDURE}

\section{A. Material and In Situ Experiments Setup}

In situ HEXRD measurements were conducted in transmission geometry at the beamline P07-EH3 (Deutsches Elektronen-Synchrotron (DESY) in Hamburg, Germany). Cylindrical samples with a diameter of $5 \mathrm{~mm}$ and length of $10 \mathrm{~mm}$ of a low carbon bainitic steel (Table I) were extracted via electro-discharge machining from half the radius of an industrially produced bar (continuously cast, hot rolled, cold drawn) with a diameter of $43 \mathrm{~mm}$. The thermomechanical processing (isothermal hot uniaxial compression at $950{ }^{\circ} \mathrm{C}-$ Figure 1(a)) resulted in a partially recrystallized austenite, which is a representative condition encountered in conventional hot forging processes. A modified Bähr DIL $805 \mathrm{~A} / \mathrm{D}$ quenching and deformation dilatometer from TA instruments (Figure 1(b)) was used to reproduce the thermomechanical treatment conditions. The heating and controlled cooling procedures were conducted using an induction coil under a vacuum atmosphere. The temperature was measured with a type $\mathrm{S}$ thermocouple welded on the surface of the specimen. During the experiments, the length change of the sample was measured in the axial direction simultaneously with diffraction patterns recorded with a frequency of $5 \mathrm{~Hz}$ by a Perkin Elmer XRD 1621 area detector positioned at a distance of $1384 \mathrm{~mm}$ from the sample. The X-ray energy and the beam size were respectively $98.188 \mathrm{keV}$ and $1 \times 1 \mathrm{~mm}$. The X-ray beam was not moved during the experiments.

\section{B. Data Processing}

The 2D diffraction data were integrated into conventional intensity vs $2 \theta$ patterns using the program pyFAI (python library) in two separate procedures. The first of these procedures is the full azimuthal integration over the Debye-Scherrer rings to perform quantitative phase analysis using $\{110\},\{200\},\{211\},\{220\}$ and $\{310\}$ ferrite peaks and austenite $\{111\},\{200\},\{220\},\{311\}$ and $\{222\}$ reflections in order to get the best possible statistics to remove texture effects. This procedure was also adopted for the lattice parameter determination in the undeformed sample. In the sample subjected to the thermomechanical processing, the resulting DebyeScherrer rings are ellipses with different eccentricity due to lattice strains. ${ }^{[8]}$ As a consequence, full azimuthal integration of the diffraction rings will result in peaks with asymmetric shape, which leads to uncertainties in the lattice parameter determination. In order to obtain representative measurements of the lattice parameter in the deformed sample, rather than full integration, a sector of $20 \mathrm{deg}$ was azimuthally integrated at $45 \mathrm{deg}$ (35 $\mathrm{deg} \rightarrow 55 \mathrm{deg}$ ) on the diffraction rings (see Figure 1(b)), which was assumed an angular range that contains positive and negative lattice strains.

The diffraction patterns were analyzed by the Rietveld refinement using TOPAS software version V4.2 from Bruker-AXS, Karlsruhe, Germany. The instrumental function was determined using a $\mathrm{LaB}_{6}$ standard powder with a thickness of $6 \mathrm{~mm}$.

Additionally, a Pseudo-Voigt fit function was implemented using MATLAB routines for the extraction of the Full Width at Half Maximum (FWHM) values of the peaks. The average carbon content in solution in austenite during the bainitic transformation was determined using the measured lattice parameter $\left(a_{\gamma} \pm 0.000016 \mathrm{~nm}\right)$ corrected with a temperature dependence given in Reference 9 and finally used in the Dyson and Holmes equation. ${ }^{[10]}$ It should be remarked that the diffraction methods are sensitive to internal stresses, for example, the evaluation of carbon in solution based on the austenite lattice parameter may be submitted to uncertainties due to the effects of the type II stresses in the polyphase materials. ${ }^{[1]}$ On the other hand, these effects were not addressed in the present work since they are assumed to be not relevant under a relatively slow cooling rate.

The early stages of the bainitic formation during continuous cooling were evaluated through the qualitative analysis of the evolution of the intensity of the $\{110\} \alpha$ diffraction ring. In this approach, the Debye-Scherrer rings were integrated over an azimuthal range of 0 to $360 \mathrm{deg}$ in 720 sectors, and the maximum intensity was plotted against the $2 \theta$ angle in color 2D diagrams.

\section{Ex Situ Investigations}

Specimens for metallography analysis were sectioned in the longitudinal direction and prepared by the standard procedures for microstructural analysis (grinding and polishing). The samples were then etched with Nital 3 pet and examined under a VEGA II XLH TESCAN scanning electron microscope (SEM).

Electron backscatter diffraction (EBSD) mapping was performed using Philips XL 30 equipment operating at $25 \mathrm{keV}$, a working distance of $8.4 \mathrm{~mm}$, a sample-tilt angle of $75 \mathrm{deg}$, and a step-size of $0.1 \mu \mathrm{m}$. The data were processed in the Orientation Imaging Microscopy 
Table I. Chemical Composition (Mass Pct) of the Investigated Steel

\begin{tabular}{lccccccccr}
\hline $\mathrm{C}$ & $\mathrm{Mn}$ & $\mathrm{Si}$ & $\mathrm{Cr}$ & $\mathrm{Mo}$ & $\mathrm{Ni}$ & $\mathrm{Cu}$ & $\mathrm{N}$ & $\mathrm{P}$ & $\mathrm{S}$ \\
\hline 0.16 & 1.48 & 1.22 & 1.19 & 0.27 & 0.067 & 0.11 & 0.01 & 0.0097 & 0.0154 \\
\hline
\end{tabular}

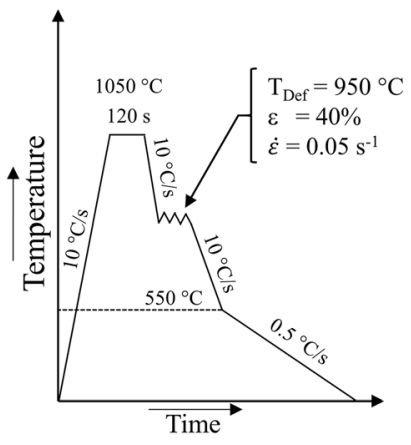

(a)

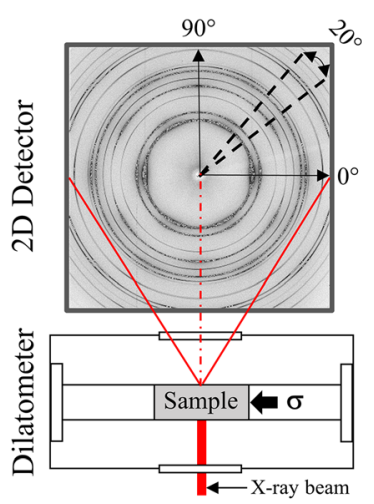

(b)
Fig. 1-(a) Illustration of the thermomechanical treatment and $(b)$ schematic representation of the experimental setup for in situ synchrotron X-ray diffraction. $T_{\text {Def }}$ stands for the deformation temperature.

(OIM) data analysis software from EDAX. Finally, Vickers hardness measurements were carried out with a load of $9.8 \mathrm{~N}$.

\section{RESULTS AND DISCUSSION}

\section{A. Bainite Formation and Kinetics}

Figures 2(a) and (b) shows the evolution of the $\{111\} \gamma$ and $\{110\} \alpha$ reflections for undeformed and deformed austenite in a temperature range from $550{ }^{\circ} \mathrm{C}$ to $495{ }^{\circ} \mathrm{C}$. It can be observed that the intensity of $\{110\} \alpha$ in Figure 2(a) starts to become visible at $530{ }^{\circ} \mathrm{C}$, while for deformed condition (Figure 2 (b)), it appears at $545^{\circ} \mathrm{C}$, which is significantly higher compared with the undeformed state. The bainite formation in the described temperature range is expected mainly due to the low carbon content of steel. ${ }^{[12]}$ The relative higher width of the $\{110\} \alpha$ reflection (Figure 2(b)) is associated with an increase in nucleation sites for bainite promoted by the deformation process. It is interesting to notice that, although the intensities in Figure 2(b) form first, the reflection $\{110\} \alpha$ in Figure 2(a) seems to develop relatively faster from $510{ }^{\circ} \mathrm{C}$, which indicates that deformation retarded the transformation in the deformed austenite.

Figure 2(c) shows the evolution of the bainitic transformation kinetics based on the bainite and austenite phase contents determined from the diffraction patterns. The transformation kinetics are relatively fast between 525 and $400{ }^{\circ} \mathrm{C}(\approx 73$ mass pct of bainite formed in 7.5 minutes), which is expected for the present steel, mainly because of the relatively low amount of carbon to be partitioned. ${ }^{[13]}$ The maximum fraction of bainite is very similar for both samples $(\approx 86$ mass pct). This finding is not reported by Reference 14, which documented that the maximum attainable fraction of bainite decreases in deformed austenite.

The overall kinetics of the transformation during the continuous cooling seems to be slightly retarded by the prior deformation of austenite, as observed in References 15 and 16. According to Kang et al., ${ }^{[17]}$ the structures, namely "granular structure" and "granular bainite," form respectively at medium temperatures in low carbon alloy steels, and could be detected through to the inflections points on the phase transformation kinetics curve. Lee et al. ${ }^{[18]}$ observed similar behavior in their investigation, which was attributed to a transition temperature between upper and lower bainite during continuous cooling. However, other investigations ${ }^{[7,19]}$ reported no conclusive evidence about the reasons for these inflection points on the phase transformation kinetics curve during the continuous cooling in medium carbon steels. In the present investigation, the phase transformation kinetics from HEXRD (Figure 2(c)) and dilatometry data (Figure 2(d)) provide no clear evidence of additional inflection points related to the formation of the structures reported by Kang et al. in their work. Thus, it can be inferred that the slow kinetics of transformation in deformed austenite apparently is not related to the suppression one of specific bainite morphology by the deformation. On the other hand, in deformed austenite, the residual lattice strains can hinder the progress of the bainitic transformation by the mechanical stabilization of austenite, ${ }^{[14,20]}$ providing a possible explanation for the slower kinetic in the range of $500{ }^{\circ} \mathrm{C}$ to $350{ }^{\circ} \mathrm{C}$.

In Figure 2(d), the transformation from deformed austenite shows a significantly higher transformation strain, while the evolution of phase fractions determined by X-ray is very similar (Figure 2(c)). The abnormal transformation strain behavior during the bainitic transformation from deformed austenite was also found in the medium, ${ }^{[21,22]}$ and high carbon ${ }^{[23]}$ steels. This phenomenon has been associated with the ability to promote specific crystallographic variants due to the variant selection induced by deformation. ${ }^{[22]}$ Thus, it might lead to a misinterpretation of the transformation kinetics as well as the estimation of the phase fraction using the dilatometer data.

In Figures 3(a) and (c), a qualitative estimation of the prior austenite grain size before the transformation can be made through the analysis of $\{h k l\}$ reflection of austenite since the intensity distribution on the Debye-Scherrer rings holds information about grain size, grain refinement and coarsening. ${ }^{[24]}$ For the undeformed austenite, the relatively coarse grain size is 


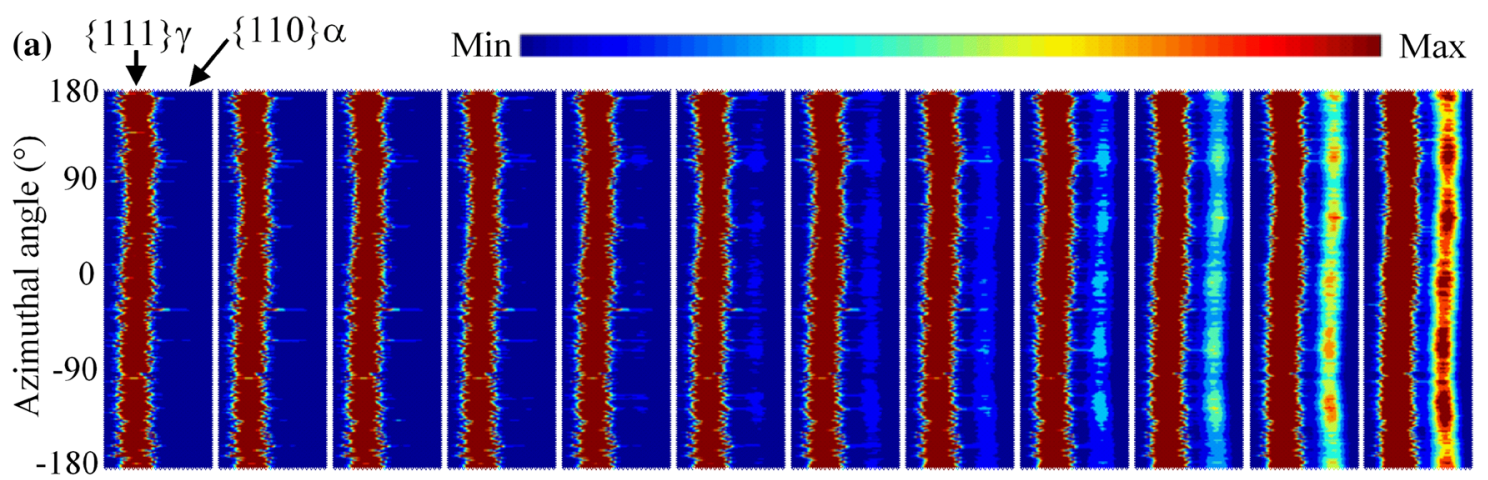

(b) $\quad 550{ }^{\circ} \mathrm{C} \quad 545^{\circ} \mathrm{C} \quad 540{ }^{\circ} \mathrm{C} \quad 535^{\circ} \mathrm{C} \quad 530^{\circ} \mathrm{C} \quad 525^{\circ} \mathrm{C} \quad 520^{\circ} \mathrm{C} \quad 515^{\circ} \mathrm{C} \quad 510^{\circ} \mathrm{C} \quad 505^{\circ} \mathrm{C} \quad 500^{\circ} \mathrm{C} \quad 495^{\circ} \mathrm{C}$

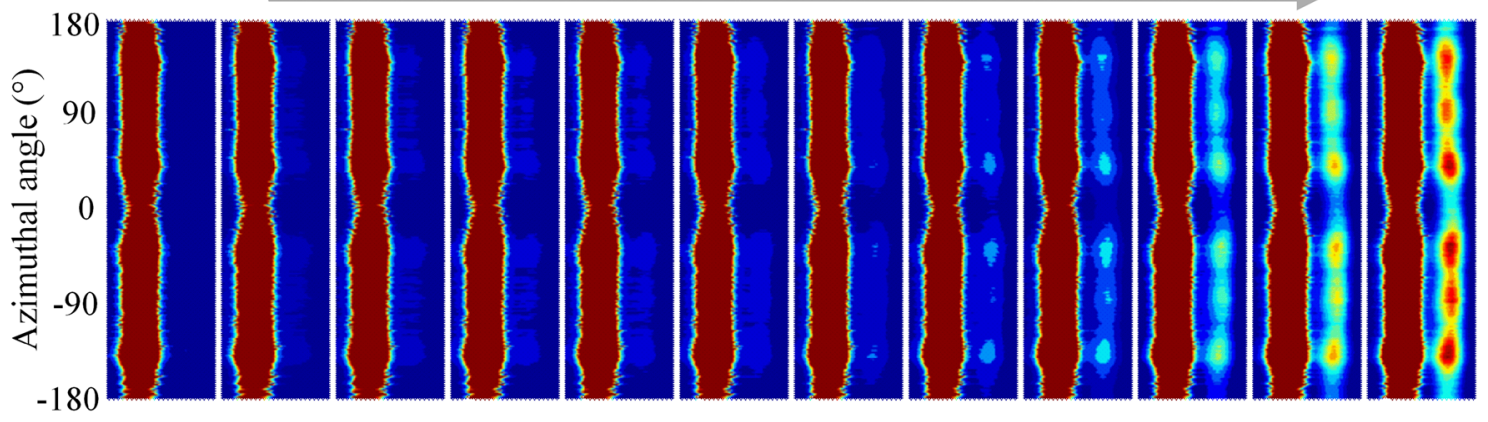

(c)

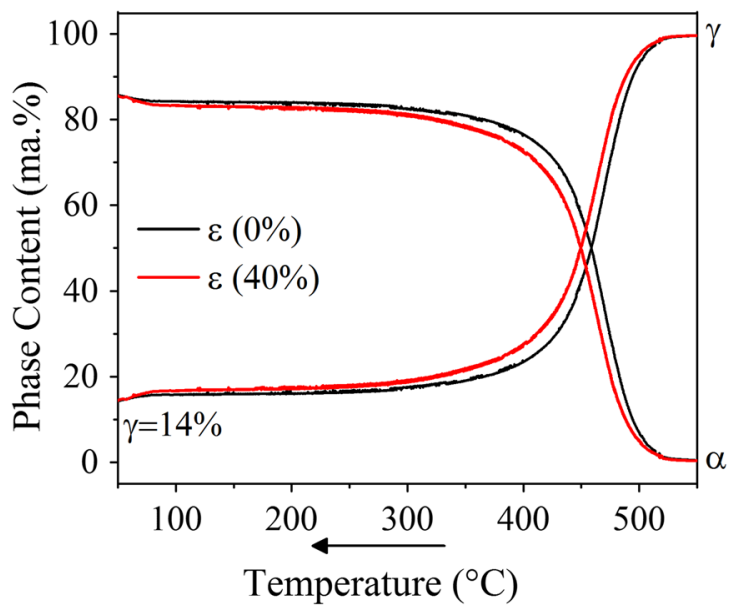

(d)

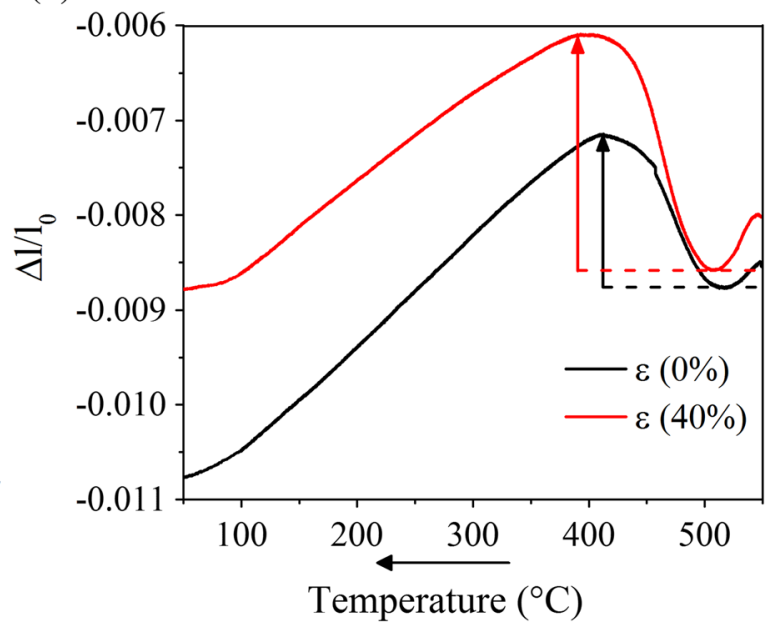

Fig. 2 - Color 2D plots of the evolution of $\{111\} \gamma$ and $\{110\} \alpha$ Bragg reflections for azimuthal range of 0 to 360 deg at the first stages of bainitic transformation during continuous cooling: $(a) \varepsilon=0$ pct and $(b) \varepsilon=40 \mathrm{pct},(c)$ phase transformation kinetics from synchrotron data, $(d)$ evolution of the relative length change curves during continuous cooling. The azimuthal angle of 0 and 90 deg shown in (a) are axial and radial directions, respectively (Color figure online).

reflected in the discontinuous Debye-Scherrer rings obtained (see the inset in detail in Figure 3(a)). In the deformed austenite, homogeneous diffraction rings are observed (Figure 3(c)), indicating both contributions from relatively smaller grain size and the lattice defects promoted by deformation. For continuous cooling transformation, relatively small grain size has been shown to lower the bainite temperature formation. ${ }^{[25]}$ According to results from isothermal treatments in different steels without prior deformation, ${ }^{[26]}$ a reduction in the prior austenite grain can reduce the overall kinetics for rapid growth from a limited number of nucleation sites. However, some of these results are based only on heat treatment experiments without any deformation step. In the present work, a relatively smaller austenite grain size appears to accelerate the early stages of bainite formation without any increase in the overall kinetics of the transformation. These results are in contradiction with the findings reported by Reference 18 while others in Reference 27, did not find significant effects decreasing the prior austenite grain size on the bainitic transformation rate.

At room temperature (Figures 3(b) and (d)), the 2D plots show a significant variation of intensities along 

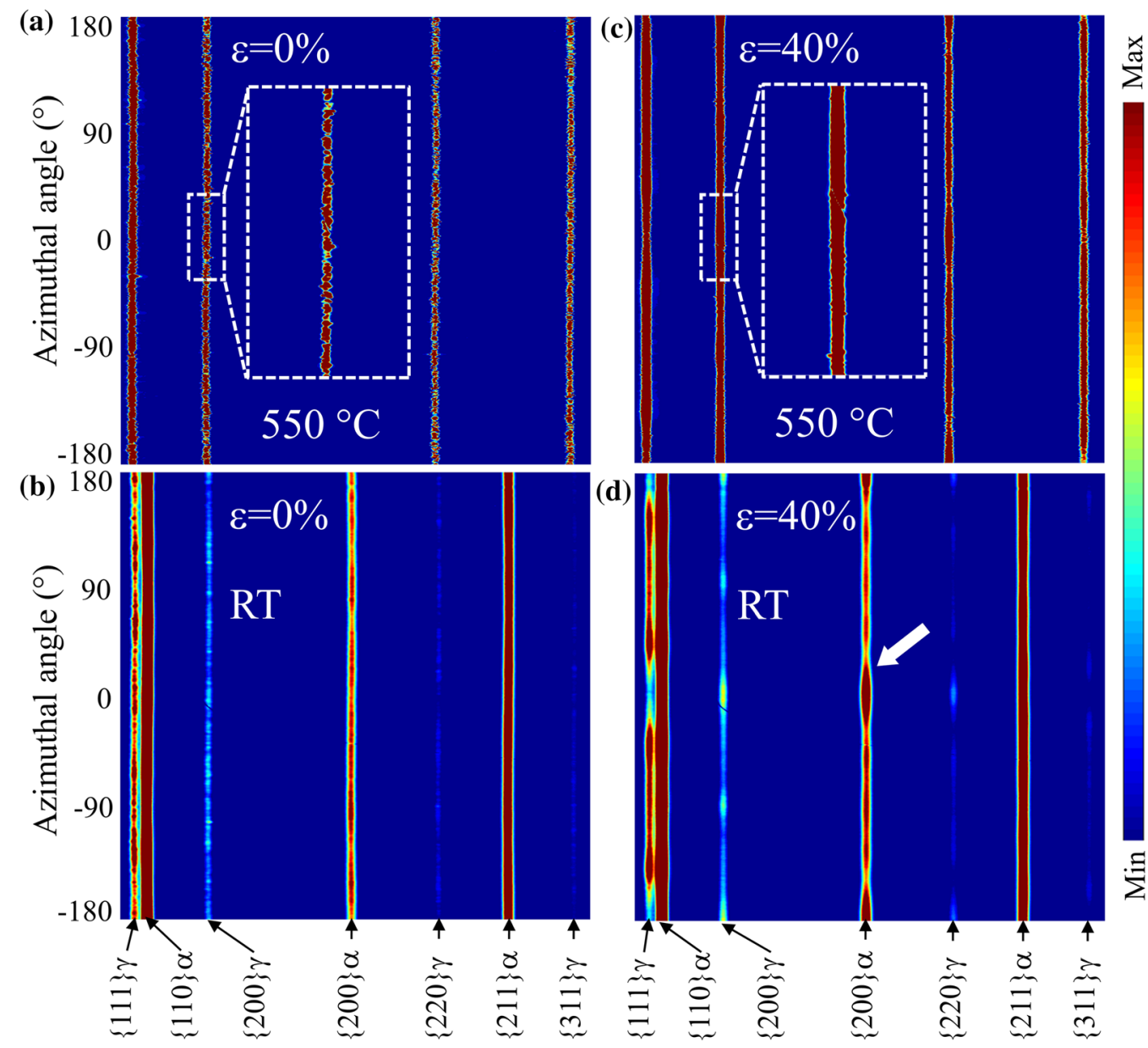

Fig. 3-Color 2D plots of the first Bragg reflections covering the azimuthal range from 0 to 360 deg. (a) $550{ }^{\circ} \mathrm{C}$ before the bainitic transformation $\left(\varepsilon=0\right.$ pct). (b) Room temperature $(\mathrm{RT})$ after the bainitic transformation $(\varepsilon=0$ pct $)$. (c) $550{ }^{\circ} \mathrm{C}$ before the bainitic transformation $(\varepsilon=40 \mathrm{pct})$. (d) Room temperature after the bainitic transformation $(\varepsilon=40 \mathrm{pct})$. The azimuthal position 0 deg represents the axial direction (Color figure online).

with the bainite and austenite reflections, which indicate texture effects. As expected, for the deformed condition, the texture is more pronounced (see the bainite reflection $\{200\}$ indicated by the arrow in Figure 3(d)).

\section{B. Lattice Parameter and Peak Broadening}

The results from the evolution of the lattice parameter of untransformed austenite during the bainitic transformation are shown in Figure 4(a). The straight dashed line represents the theoretical thermal contraction of the lattice parameter. As the temperature decreases during continuous cooling, an increase in the measured lattice parameter is observed for both the undeformed and deformed samples. This increase is due to the partitioning of carbon from bainitic ferrite to residual austenite. ${ }^{[7,28]}$

In Figure 4(b), before the bainite formation, the calculated carbon content in solution $(C \gamma)$ is around 0.17 mass pct, which corresponds quite well to the nominal carbon content of the investigated steel. As the transformation progresses, the carbon in solution increases gradually, reaching values in the range of
0.65 to 0.68 mass pet at $300{ }^{\circ} \mathrm{C}$. Figures $4(\mathrm{a})$ and (b) indicate that the carbon enrichment of austenite was lower in the deformed sample presenting a similar tendency found in the phase content evolution already shown in Figure 2(c). It is interesting to note that even the austenite final phase fraction was practically the same, the final carbon content in the remaining austenite is slightly lower for the undeformed sample. The interface between the prior formed ferrite and the residual austenite $(\alpha / \gamma)$ promotes a chemical heterogeneity of carbon in austenite, as reported in the literature. ${ }^{[29]}$ However, as shown in Figures 2(a) and (b), in both samples, the transformation starts from a fully austenitic microstructure. Thus, prior ferrite before the transformation is not responsible for the relatively low carbon content in deformed austenite. The reduction of carbon partitioning into deformed austenite has been reported in the literature, and it is explained in terms of clustering and segregation of the carbon atoms to lattice defects, i.e., the deformation at high temperatures can lead to segregation of carbon atoms to regions of high dislocations density forming Cottrell atmospheres. ${ }^{[30]}$ $\mathrm{X}$-ray diffraction experiments cannot determine the 


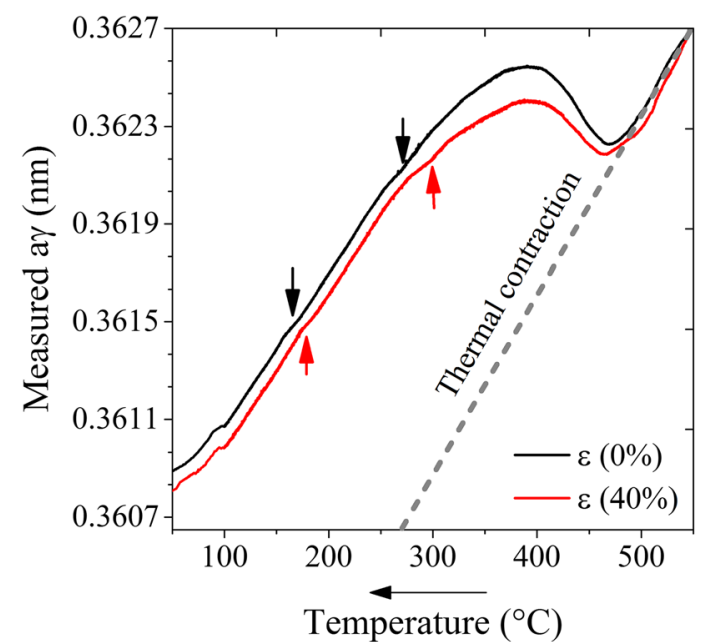

(a)

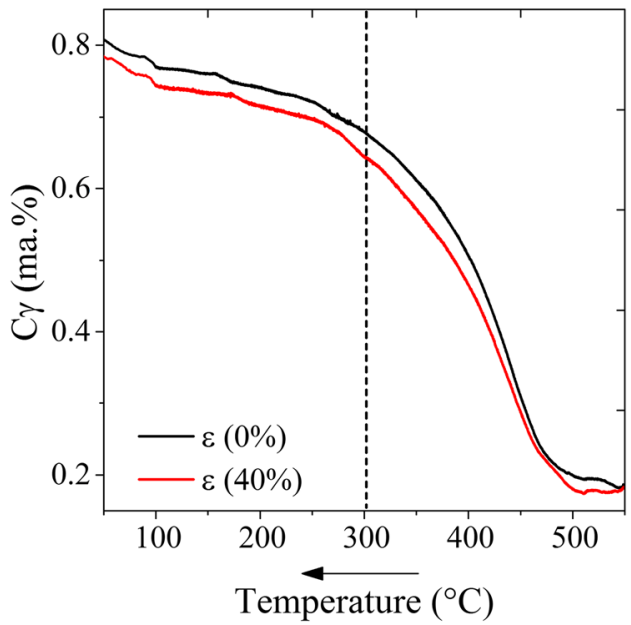

(b)

Fig. 4-(a) Evolution of the measured lattice parameter of austenite and $(b)$ evolution of carbon content in solution in austenite $\left(C_{\gamma}\right)$ during continuous cooling transformation for undeformed and deformed austenite. The straight dash line represents the end of bainitic transformation (Color figure online).

carbon trapped at lattice defects since the carbon atoms are present in regions of the lattice that are already dilated due to the strain field of the defect, thus contributing much less to lattice parameter expansion than when placed in the perfect lattice. ${ }^{[31]}$

Local changes in the lattice parameter of austenite and carbon content below $300{ }^{\circ} \mathrm{C}$ (marked with black and red arrows at Figure 4(a)) are not related to the carbon partitioning process since the transformation is almost already completed at $300{ }^{\circ} \mathrm{C}$ (Figure 2(c)). Rather than that, these effects are expected to be in relation to the martensitic transformation of small regions with lower carbon austenite trapped between the bainite subunits, which is expected when the carbon-enriched austenite is cooled down to a temperature below the martensite start temperature (Ms). ${ }^{[7,32,33]}$ Such transformation can induce changes in the lattice parameter values of austenite due to stresses, ${ }^{[34,35]}$ consequently increasing the average calculated carbon content in solution, which could explain the origin of this behavior.

Furthermore, the fluctuations in the austenite lattice parameter seem to take place at slightly higher temperatures for the deformed sample. Considering that the martensitic transformation in carbide-free bainite steels is dependent on the carbon content of the residual austenite, ${ }^{[28]}$ an increase in Ms temperature is expected due to the relatively lower carbon content in the deformed sample.

The evolution of the FWHM values from the reflections $\{220\} \gamma$ and $\{211\} \alpha$ during the bainitic transformation are shown in Figures 5(a) through (c), respectively. Before the transformation starts, the higher starting values $(>\approx 10 \mathrm{pct})$ for the $\{220\} \gamma$ reflection in deformed austenite are attributed to the existence of residual lattice strain in the microstructure. In undeformed austenite, instabilities in the FWHM values (indicated by an ellipse in Figure 5(a)) are related to the coherent and semi-coherent strains arising from the nucleation of bainite which results in the generation of defects and plasticity in the surrounding austenite matrix. ${ }^{[36]}$ Similar tendencies were not observed in the same range of temperature for the deformed condition, which is believed to be associated with the impingement phenomenon. As the transformation progresses, the associated broadening effects in austenite are related to the plastic deformation due to bainite growth, the small crystallite size of the carbon-enriched austenite ${ }^{[37]}$ and the local variations of the carbon concentration inherent to the transformation. ${ }^{[38]}$

It is interesting to note that the overall broadening shown in Figure 5(b) for the $\{220\} \gamma$ reflection is decreased both in terms of rate and maximum values reached in deformed austenite. Such behavior indicates that the growth of bainite is possibly hindered by the lattice defects in the deformed austenite since the austenite peak broadening effects are directly related to the progress of the transformation. Furthermore, the pronounced broadening effect in undeformed austenite reflection is in relative good accordance with the observed higher carbon content in austenite shown in Figure 4(b).

As the temperature decreases to around $300{ }^{\circ} \mathrm{C}$, the FWHM values from austenite reach the maximum and start to drop, as shown in Figure 5(b). This result suggests that the interface strain was relaxed, resulting in a redistribution of dislocations toward phase boundaries (retained austenite and bainite subunits) after the transformation ceases. A similar phenomenon has been observed in Ni-base alloys under plastic deformation ${ }^{[39]}$ and during the bainitic transformation under load. ${ }^{[40]}$ Comparing the overall drop in FWHM values (represented by $\Delta$ in the inset in Figure 5(b)), a slightly lower drop can be observed in the deformed austenite, suggesting that the interface strain relaxation is affected in some way by the developed microstructure. It is suggested that this phenomenon might play an important role in mechanical stability on film-like retained 


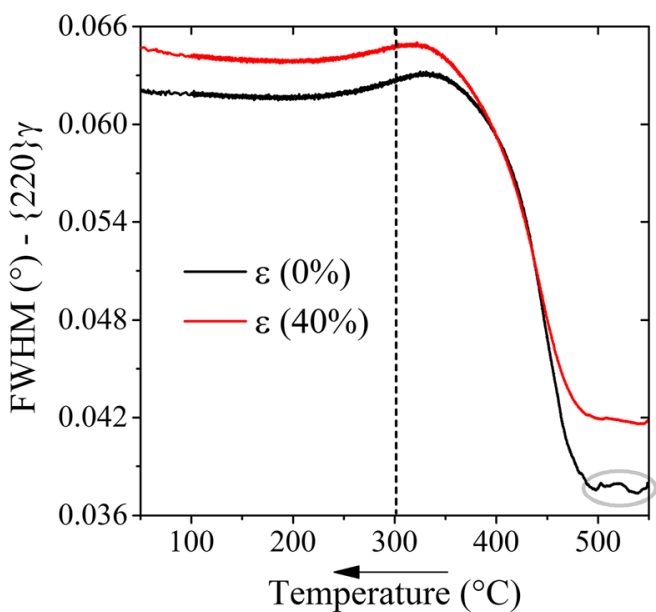

(a)

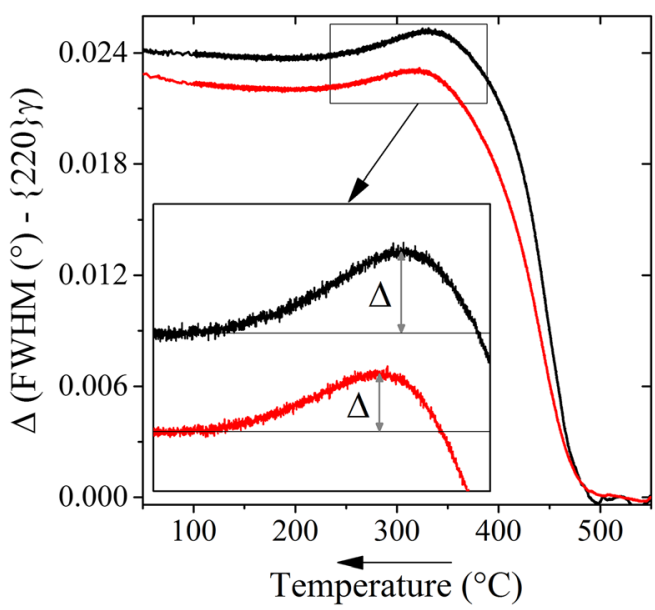

(b)

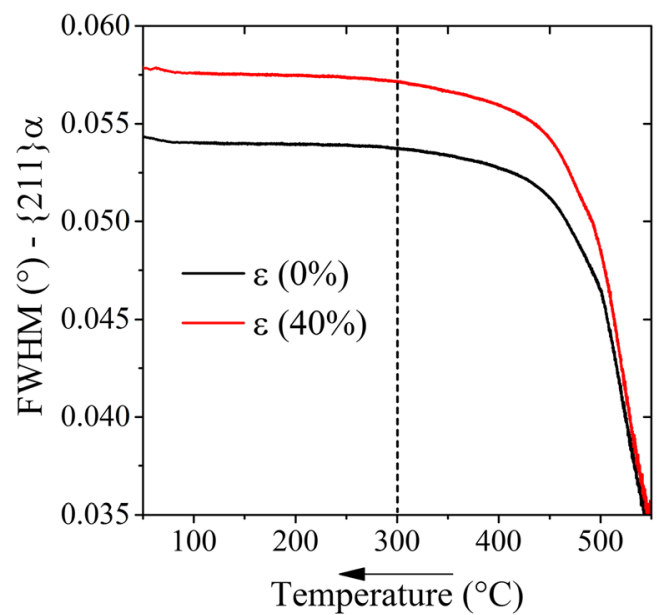

(c)

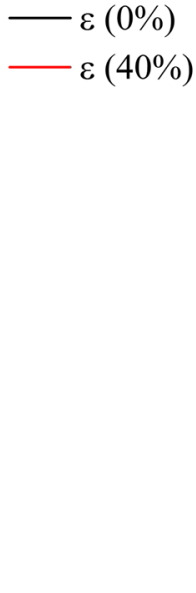

Fig. 5-(a) Evolution of the FWHM of the austenite $\{220\}$ peak; (b) overall increase ( $\Delta$ ) in the FWHM of austenite; and (c) FWHM of bainite $\{211\}$ peak during continuous cooling transformation for undeformed and deformed austenite. The vertical straight dash line in (a) and (b) represents the end of bainitic transformation (Color figure online).

austenite. However, further studies need to be carried out in order to check this point.

The evolution of the peak broadening for the $\{211\} \alpha$ reflection (from undeformed and deformed austenite) is plotted in Figure 5(c). For both conditions, the broadening effect is associated with the growth of subunits accompanied with the increase in the dislocation density when the temperature of transformation decreases. ${ }^{[1]}$ The austenite deformation leads to an increase in the density of nucleation sites for bainite subunit. ${ }^{[13,14]}$ It is thus expected that the increase in the density of these subunits leads to higher FWHM values. Considering the existence of the carbon atoms segregated in the lattice defects of the bainitic ferrite forming Cottrell atmospheres, ${ }^{[42,43]}$ an increasing density of bainite subunits during the transformation in deformed austenite would result in more carbon atoms trapped into bainitic ferrite lattice defects forming clusters. Thus, reducing the available carbon content to be partitioned into austenite.
Still considering Figure 5(c), it is possible to note that the FWHM values do not show any significant drop around $300{ }^{\circ} \mathrm{C}$, as seen in austenite in Figure 5(b). This behavior is explained by the low dislocation mobility in the bainitic ferrite phase since the density and arrangement of dislocations inside grains generally affect the peak broadening of the X-ray profile. ${ }^{[39]}$ Finally, it is observed that the peak broadening in the bainitic ferrite reflections remains unchanged during the subsequent cooling, demonstrating the absence of the formation of a new dislocation network within the bainitic ferrite subunits. ${ }^{[36]}$

\section{Microstructure After In Situ Experiments}

Representative SEM micrographs of undeformed and deformed conditions from the previous in situ experiments are shown in Figures 6(a) and (b), respectively. Typical granular bainite (GB) morphology characterizes the microstructure, ${ }^{[7,44}$ which is more refined in 
(a)

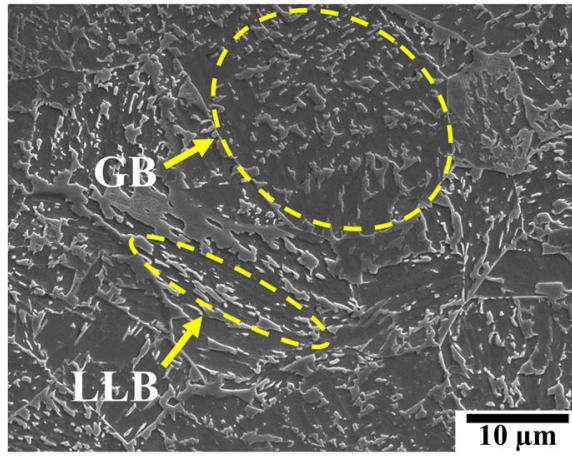

(c)

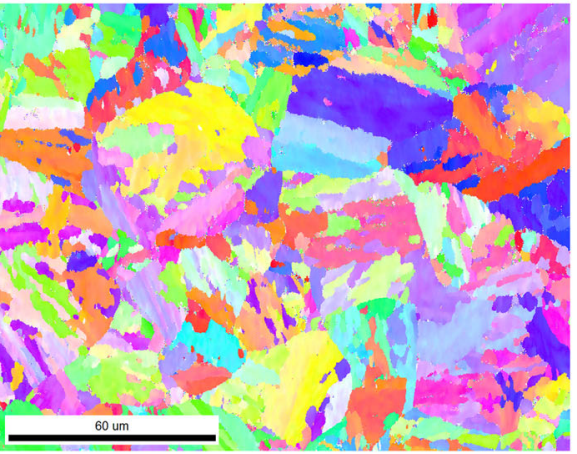

(e)

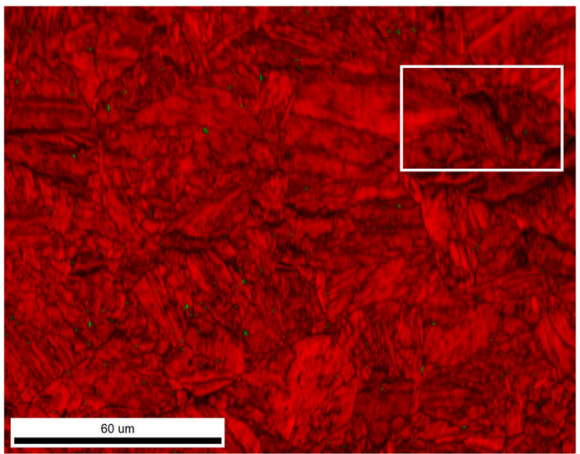

(b)

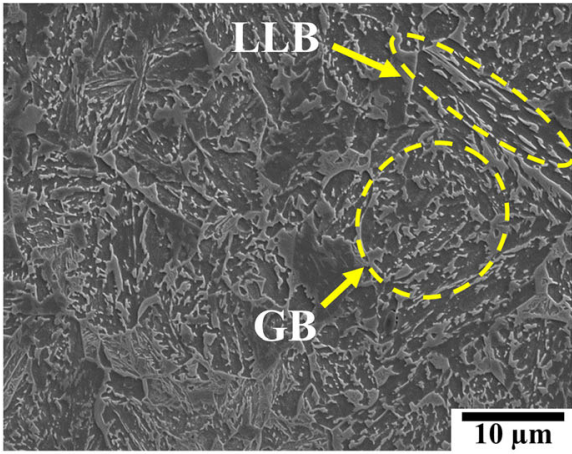

(d)
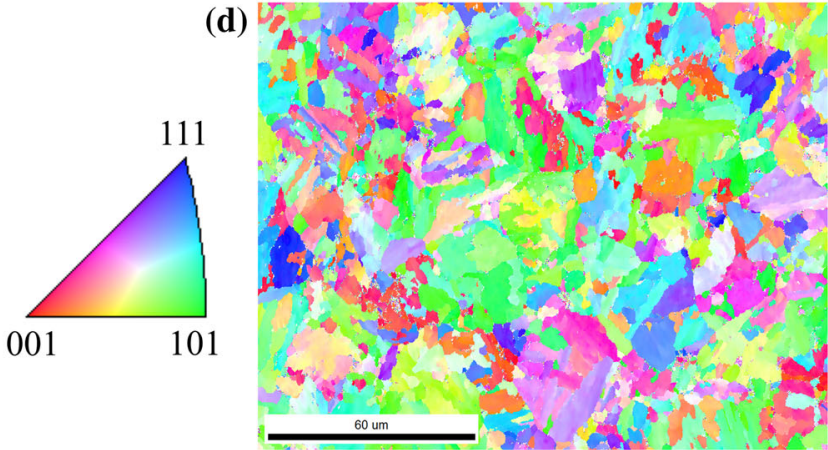

(f)

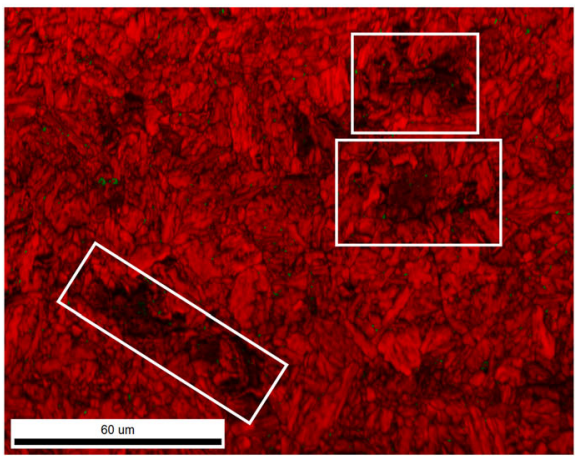

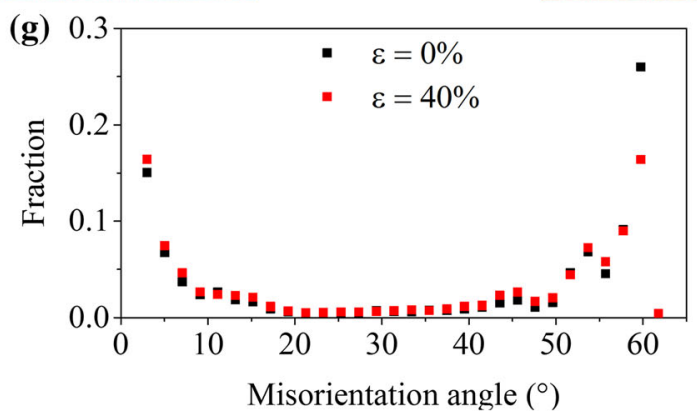

Fig. 6- $(a)$ and $(b)$ SEM-micrographs of granular bainite formed in continuous cooling. $(c)$ and $(d)$ IPF of the body-centered cubic (bcc) phase. $(e)$ and $(f)$ IQ maps of the bcc phase. (g) Boundary misorientation distribution. $\varepsilon=0$ pct in (a, c and e) and $\varepsilon=40$ pct in (b, d and f). CA stands for the compression axis, and GB and LLB denote granular bainite and lath-like bainite, respectively (Color figure online).

deformed austenite (Figure 6(b)). It is possible to identify a small fraction of lath-like bainite morphology (LLB) in both microstructures, which leads to the conclusion that the deformation process does not suppress its formation. The mixture of structures (randomly and oriented bainite structures) found in microstructure is consistent with some aspects of the bainite structures reported in low carbon alloy steels. ${ }^{[17]}$
Considering that the bainitic ferrite is stronger attacked by the etchant, the structures in relief on the micrographs are a mixture of martensite and retained austenite ${ }^{[45]}$ The formation and the shape of these structures, known as martensite-austenite constituents in the literature, are mainly controlled by the cooling and the nucleation rate. ${ }^{[13]}$ Since the deformation process increased the number of sites for bainite growth (as expected from the FWHM evolution shown in 
Figure 5(c)) and changed the amount of carbon in solution in austenite (Figure 4(b)), these conditions seem to increase the density of martensite-austenite constituents in the bainitic ferrite matrix. The microstructural refinement of granular bainite and the amount of martensite-austenite constituents lead to an increase in hardness values from $344 \pm 4\left(\mathrm{HV}_{1}\right)$ to $371 \pm$ $16\left(\mathrm{HV}_{1}\right)$. Finally, it is apparent that there is no polygonal ferrite formation in the microstructure.

From EBSD results in Figures 6(c) and (d), it is evident that the crystallographic structure of the transformation of deformed austenite is finer and more fragmented. These refinement effects result from the strengthening effect of austenite by deformation, which leads to the refinement of blocks, and the creation of a different variant selection within the austenite grain. ${ }^{[46]}$ It can be inferred that the variants presented in Figure 6(c) seem to contain similar fractions. However, in Figure 6(d), it can be qualitatively interpreted that the variants close to the orientation [101], seem to have more fraction indicating their prevalence over others.

In Figures 6(e) and (f), the dark areas (some of them indicated by rectangles) are associated with the lower image quality (IQ), resulting from a high concentration of lattice defects like dislocations for example. In literature, several investigations correlate low IQ regions with relatively large areas of martensite-austenite constituents. ${ }^{[7,28,47-49]}$ Presumably, the increase in density of dark regions in Figure 6(f) suggests an increase in martensite-austenite constituents in the deformed sample. As already shown in HEXRD experiments (Figure 4(b)), the carbon solution in austenite during the partitioning process was lower in deformed austenite. This condition may reduce the thermal stability of remaining retained austenite to transform into martensite during continuous cooling transformation below $300{ }^{\circ} \mathrm{C}$.

Finally, the effects of deformation on the boundary misorientation distributions are shown in Figure 6(g). The austenite deformation appears to increase the prominence of low-misorientation boundaries and reduce the prominence of the near-60 deg misorientations. ${ }^{[5]}$ The overall results of the distribution of misorientation angles in the present work are similar to the classification of granular bainite obtained by continuous cooling proposed in the Reference 50.

In Figure 7(a), no clear transformation texture is observed in the inverse pole figure (IPF) for the undeformed sample. In the deformed sample (Figure 7(b)), transformation texture in the $\{111\} \alpha$ and $\{100\} \alpha$ peaks is developed. These results are in good agreement with previous studies on ausforming of low-alloy low-carbon bainitic steel, ${ }^{[51]}$ especially the strong texture around $\{111\} \alpha$ peak.

Figures 7(c) and (d) shows the $\{110\} \alpha$ pole figures from EBSD measurements for undeformed and deformed samples, respectively. For both conditions, it is clear that most intensity peaks are rather broad, possibly associated due to close but not equivalent crystallographic orientations. ${ }^{[52]}$ In the undeformed sample (Figure 7(c)), the intensities are randomly distributed, and apparently, a significant number of

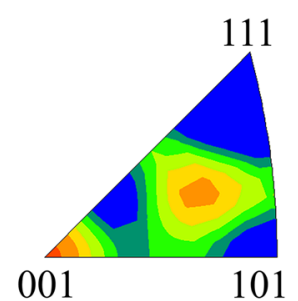

(a)

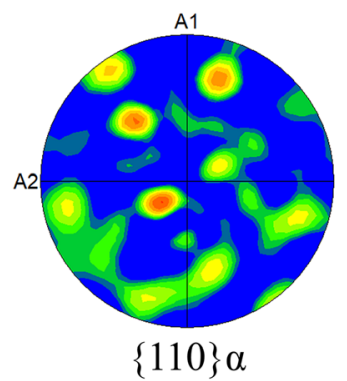

(c)

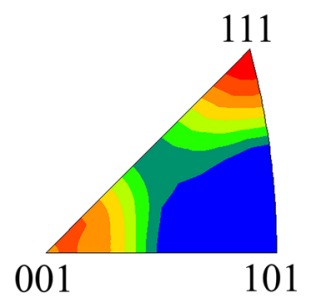

(b)

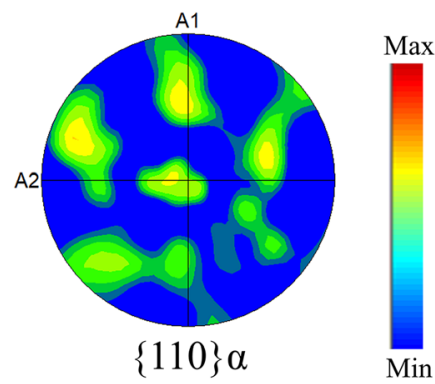

(d)
Fig. 7-(a) and (b) IPFs of bcc phase. (c) and (d) $\{110\} \alpha$ pole figures. $\varepsilon=0$ pct in (a and c) and $\varepsilon=40$ pct in (c and d) (Color figure online).

variants are present. In contrast, there seems to be a significant reduction of crystallographic variants in Figure 7(d). These results are consistent with the work performed by Castellanos et al., ${ }^{[2]}$ which reported similar evidence in ausforming experiments, suggesting that variant selection may have occurred, and it is correlated with the higher transformation anisotropy. Therefore, considering that the transformation strain is affected due to variant selection, ${ }^{[53]}$ the occurrence of this phenomenon in deformed austenite during continuous cooling might be a reasonable explanation for the higher transformation strain in the deformed sample (see Figure 2(d)).

\section{CONCLUSIONS}

The bainitic transformation from deformed austenite during continuous cooling in a low carbon steel was comprehensively studied by in situ high-energy X-ray diffraction. The results lead to the following conclusions:

1. At early stages, the bainite grows first in deformed austenite, but its overall kinetics is lower during the ongoing transformation due to the mechanical stabilization of austenite.

2. No clear evidence of secondary inflection points on the dilatometer signal and phase content (from synchrotron data) were found during the continuous cooling transformation.

3. The growth of bainite from deformed austenite leads to a lower carbon enrichment in austenite. This condition reduced the stability of residual 
austenite to transform into martensite during cooling.

4. The evolution of the FWHM of bainite and austenite reflections provides good information about the transformation behavior. The austenite peak broadening was more pronounced in the undeformed sample than in the deformed one, but this tendency was inverse for the bainite reflection.

5. The obtained microstructures from undeformed and deformed austenite are predominantly granular bainite and retained austenite. The thermomechanical processing does not increase or decrease the maximum attainable fraction of bainite in the present steel but clearly refines the microstructure from deformed austenite due to an increase in nucleation sites.

6. Higher dilatation strain was measured in the transformation from deformed austenite, which is related to variant selection in textured austenite.

\section{ACKNOWLEDGMENTS}

This study was financed in part by the Coordenação de Aperfeiçoamento de Pessoal de Nível Superior Brasil (CAPES) - Finance Code 001 and the Deutsche Forschungsgemeinschaft_DFG (ZO 140/21-1). The authors gratefully acknowledge DESY for provision of beamtime as well as Norbert Schell and Andreas Stark from Helmholtz-Center-Geesthacht at beamline P07 (PETRA III-DESY) for support during the synchrotron experiments.

\section{REFERENCES}

1. T. Sourmail: HTM J. Heat Treat. Mater., 2017, vol. 72, pp. 371-78.

2. H.K.D.H. Bhadeshia: Bainite in Steels: Theory and Practice, 3rd ed., Maney Publishing, Wakefield, 2015.

3. D. Quidort: ISIJ Int., 2002, vol. 42, pp. 1010-17.

4. V.M. Khlestov, E.V. Konopleva, and H.J. Mcqueen: Can. Metall. Q., 2014, vol. 37, pp. 75-89.

5. R.W. Regier, A. Reguly, D.K. Matlock, J. Choi, and J.G. Speer: Mater. Sci. Forum, 2014, vols. 783-786, pp. 85-90.

6. L. Guo, H.K.D.H. Bhadeshia, H. Roelofs, and M.I. Lembke: Mater. Sci. Technol., 2017, vol. 33, pp. 2147-56.

7. S. Reisinger, E. Kozeschnik, G. Ressel, J. Keckes, A. Stark, S. Marsoner, and R. Ebner: Mater. Des., 2018, vol. 155, pp. 475-84.

8. K. Yan, K.D. Liss, I.B. Timokhina, and E.V. Pereloma: Mater. Sci. Eng. A, 2016, vol. 662, pp. 185-97.

9. S.M.C. Van Bohemen: Scr. Mater., 2013, vol. 69, pp. 315-18.

10. D.J. Dyson and B. Holmes: J. Iron Steel Inst., 1970, vol. 208, pp. $469-74$

11. J. Epp: Mater. Res. Proc., 2016, vol. 2, pp. 283-88.

12. S.M.C. van Bohemen: Mater. Sci. Technol., 2011, vol. 28, pp. $487-95$.

13. X. Liang and A.J. Deardo: Metall. Mater. Trans. A, 2014, vol. 45 A, pp. $5173-84$

14. P.H. Shipway and H.K.D.H. Bhadeshia: Mater. Sci. Technol., 1995, vol. 11, pp. 1116-28.

15. H. Yi, L. Du, G. Wang, and X. Liu: J. Iron Steel Res. Int., 2006, vol. 13, pp. 36-39.
16. L. Du, H. Yi, H. Ding, X. Liu, and G. Wang: J. Iron Steel Res. Int., 2006, vol. 13, pp. 37-39.

17. M.K. Kang, D.M. Chen, S.P. Yang, and G.L. Hu: Metall. Trans. $A$, 1992, vol. 23, pp. 2946-47.

18. S.J. Lee, J.S. Park, and Y.K. Lee: Scr. Mater., 2008, vol. 59, pp. 87-90.

19. C. Gupta, G.K. Dey, J.K. Chakravartty, D. Srivastav, and S. Banerjee: Scr. Mater., 2005, vol. 53, pp. 559-64.

20. H.K.D. Bhadeshia: Mater. Sci. Eng. A, 1999, vols. 273-275, pp. 58-66.

21. H. Hu, H.S. Zurob, G. Xu, D. Embury, and G.R. Purdy: Mater. Sci. Eng. A, 2015, vol. 626, pp. 34-40.

22. A. Eres-Castellanos, L. Morales-Rivas, A. Latz, F.G. Caballero, and C. Garcia-Mateo: Mater. Charact., 2018, vol. 145, pp. 371-80.

23. J. He, J. Du, W. Zhang, C. Zhang, Z.G. Yang, and H. Chen: Metall. Mater. Trans. A, 2019, vol. 50A, pp. 540-46.

24. K.D. Liss and K. Yan: Mater. Sci. Eng. A, 2010, vol. 528, pp. 11-27.

25. H. Zhao, B.P.P. Wynne, and E.J.J. Palmiere: Mater. Charact., 2017, vol. 123, pp. 128-36.

26. A. Matsuzaki and H.K.D.H. Bhadeshia: Mater. Sci. Technol., 2010, vol. 15, pp. 518-22.

27. R.Y. Zhang and J.D. Boyd: Metall. Mater. Trans. A, 2010, vol. 41A, pp. 1448-59.

28. C. Hofer, H. Leitner, F. Winkelhofer, H. Clemens, and S. Primig: Mater. Charact., 2015, vol. 102, pp. 85-91.

29. K. Zhu, H. Chen, J.P. Masse, O. Bouaziz, and G. Gachet: Acta Mater., 2013, vol. 61, pp. 6025-36.

30. E.A. Ariza, A. Nishikawa, H. Goldenstein, and A.P. Tschiptschin: Mater. Sci. Eng. A, 2016, vol. 671, pp. 54-69.

31. H.K.D.H. Bhadeshia: Mater. Sci. Technol., 2015, vol. 31, pp. $758-63$.

32. S.C. Wang and J.R. Yang: Mater. Sci. Eng. A, 1992, vol. 154, pp. 43-49.

33. E. Mazancová and K. Mazanec: J. Mater. Process. Technol., 1997, vol. 64 , pp. 287-92.

34. P. Huyghe, M. Caruso, J.L. Collet, S. Dépinoy, and S. Godet: Mater. Sci. Eng. A, 2019, vol. 743, pp. 175-84.

35. M. Villa, K. Pantleon, and M.A.J. Somers: J. Alloys Compd., 2013, vol. 577, pp. 1-6.

36. R.K. Dutta, R.M. Huizenga, M. Amirthalingam, M.J.M. Hermans, H. Gao, A. King, and I.M. Richardson: in In-situ Studies with Photons, Neutrons and Electrons Scattering II, T. Kannengiesser, S.S. Babu, Y. Komizo, and A.J. Ramirez, eds., Springer, Cham, 2014, pp. 51-70.

37. R. Rementeria, J.A. Jimenez, S.Y.P. Allain, G. Geandier, J.D. Poplawsky, W. Guo, E. Urones-Garrote, C. Garcia-Mateo, and F.G. Caballero: Acta Mater., 2017, vol. 133, pp. 333-45.

38. B. Avishan, S. Yazdani, F.G. Caballero, T.S. Wang, and C. Garcia-Mateo: Mater. Sci. Technol., 2015, vol. 31, pp. 1508-20.

39. T.K. Liu, G.L. Wu, C.K. Liu, Z.H. Nie, T. Ungár, Y. Ren, and Y.D. Wang: Mater. Sci. Eng. A, 2013, vol. 568, pp. 83-87.

40. R.K. Dutta, R.M. Huizenga, M. Amirthalingam, M.J.M. Hermans, A. King, and I.M. Richardson: Metall. Mater. Trans. A, 2013, vol. 44A, pp. 4011-14.

41. C. Garcia-Mateo, F.G. Caballero, C. Capdevila, and C.G. de Andres: Scr. Mater., 2009, vol. 61, pp. 855-58.

42. C. Goulas, A. Kumar, M.G. Mecozzi, F.M. Castro-Cerda, M. Herbig, R.H. Petrov, and J. Sietsma: Mater. Charact., 2019, vol. 152 , pp. $67-75$.

43. F. Caballero, M. Miller, S. Babu, and C. Garciamateo: Acta Mater., 2007, vol. 55, pp. 381-90.

44. B.L. Bramfitt and J.G. Speer: Metall. Trans. A, 1990, vol. 21, pp. $817-29$.

45. S. Reisinger, G. Ressel, S. Eck, and S. Marsoner: Micron, 2017, vol. 99 , pp. 67-73.

46. H. Kawata, K. Sakamoto, T. Moritani, S. Morito, T. Furuhara, and T. Maki: Mater. Sci. Eng. A, 2006, vols. 438-440, pp. 140-44.

47. C. Hofer, F. Winkelhofer, H. Clemens, and S. Primig: Mater. Sci. Eng. A, 2016, vol. 664, pp. 236-46.

48. H. Zhao, B.P. Wynne, and E.J. Palmiere: Mater. Charact., 2017, vol. 123 , pp. $339-48$.

49. J.Y. Kang, S.J. Park, D.W. Suh, and H.N. Han: Mater. Charact., 2013, vol. 84 , pp. $205-15$ 
50. S. Zajac, V. Schwinnand, and K.H. Tacke: Mater. Sci. Forum, 2005, vols. 500-501, pp. 387-94.

51. G. Miyamoto, N. Iwata, N. Takayama, and T. Furuhara: J. Alloys Compd., 2013, vol. 577, pp. S528-32.

52. B. Verlinden, P. Bocher, E. Girault, and E. Aernoudt: Scr. Mater., 2001, vol. 45, pp. 909-16.
53. A. Mangal, P. Biswas, S. Lenka, V. Singh, S.B. Singh, and S. Kundu: Mater. Sci. Technol., 2014, vol. 30, pp. 1116-24.

Publisher's Note Springer Nature remains neutral with regard to jurisdictional claims in published maps and institutional affiliations. 